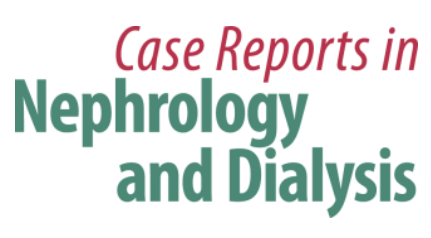

\title{
Treatment of Ureterosciatic Hernia with a Ureteral Stent
}

\author{
Koji Yanagi ${ }^{a} \quad$ Akinobu Kan $^{b} \quad$ Takehiro Sejima $^{c} \quad$ Atsushi Takenaka $^{c}$ \\ Departments of ${ }^{a}$ Urology and ${ }^{b}$ Radiological Medicine, Tsuyama Daiichi Hospital, Tsuyama, \\ and ${ }^{C}$ Division of Urology, Department of Surgery, Faculty of Medicine, Tottori University, \\ Yonago, Japan
}

\section{Key Words}

Ureterosciatic hernia · Ureteral stent · Computed tomography · Urography

\begin{abstract}
A 92-year-old woman was referred to our hospital from a family practice with the chief of complaint of vomiting. Subsequent computed tomography imaging revealed left hydroureteronephrosis without clear evidence of ureteral stones or ureteral tumors and that the lower part of the ureter was shifted to the outside of the cavum pelvis minor from the greater sciatic foramen. Retrograde pyelography was performed, and the shadow of a mass, which constricted and obstructed the distal left ureter, was observed. The patient was diagnosed with ureterosciatic hernia, and a left retrograde ureteral stent was indwelled and the hernia was repaired. Cases of ureterosciatic hernia are very rare. We describe one case of ureterosciatic hernia and review the relevant literature.

(c) 2015 S. Karger AG, Basel
\end{abstract}

\section{Introduction}

Ureteral hernia is a relatively rare disease with approximately 130 documented reports. In addition, ureterosciatic hernia is an extremely rare condition, with only 27 published reports as far as we know [1-6]. Urography and computed tomography (CT) are useful for diagnosing ureterosciatic hernia. Here, we report a case of ureterosciatic hernia that was diagnosed with CT and treated effectively using a retrograde ureteral stent. 


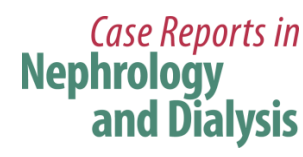

\begin{tabular}{l|l}
\hline \multicolumn{2}{l}{ Case Rep Nephrol Dial 2015;5:83-86 } \\
\hline DOI: 10.1159/000380944 & $\begin{array}{l}\text { ○ 2015 S. Karger AG, Basel } \\
\text { www.karger.com/cnd }\end{array}$ \\
\hline
\end{tabular}

Yanagi et al.: Treatment of Ureterosciatic Hernia with a Ureteral Stent

\section{Case Report}

A 92-year-old woman had nausea and vomiting with slight fever on February 24, 2014, and the symptoms continued on the following day. She was referred to the Department of Surgery of our hospital from a family practice because of suspected ileus. Left hydroureteronephrosis in the lower part of the ureter was observed on CT, and she was then referred to the Department of Urology. In the preceding 2 months, she had had a history of paralytic ileus and had undergone ileo-ileo anastomosis. She did not have any tenderness but had lower abdominal pain during the physical examination. The patient's serum white blood cell count was $18,200 / \mathrm{mm}^{3}$. Other laboratory tests of the renal function, including serum blood urea nitrogen of $17.0 \mathrm{mg} / \mathrm{dl}$ and serum creatinine of $0.8 \mathrm{mg} / \mathrm{dl}$, and urinalysis results were within normal limitations. There was no clear evidence of the presence of ureteral stones or ureteral tumors on abdominal CT imaging. The left lower part of the ureter was serpentine in shape and had been shifted to the outside of the cavum pelvis minor, with herniation into the greater sciatic foramen (fig. 1a, b). Using a cystoscope, we observed that the left ureteric orifice was pulled away from the bladder wall to the outside and seemed to form a diverticulum. The shadow of a mass was observed on retrograde pyelography. Constriction in the serpentine lower part of the ureter and the outside of the cavum pelvis minor was also observed; the distal ureter was straining the ureteric orifice (fig. 2). The patient was diagnosed as having left ureterosciatic hernia on the basis of the symptoms mentioned above. Retrograde left ureteral stenting was performed, which linearized the ureter, eliminated the mass, and reduced the constriction of the left ureteric orifice (fig. 3a, b). It was confirmed that the hernia vesicle had been fixed by doing a CT and retrograde pyelography. There is, however, a risk of recurrence. Therefore, the patient underwent an exchange of a new ureteral double-J catheter 1 year later.

\section{Discussion}

Ureteral hernia is relatively rare but generally occurs in the inguinal canal, scrotum, and femoral regions. The sciatic hiatus is divided into the greater sciatic foramen and the lesser sciatic foramen by the sacrospinal ligament. The greater sciatic foramen is divided into the suprapiriformis foramen and the infrapiriformis foramen by the piriformis muscles. Sciatic hernia is a hernia that occurs through the greater sciatic foramen and the lesser sciatic foramen. Ureterosciatic hernia can develop as a result of the loss of the partial pelvic fascia, atrophy of the musculus piriformis, adhesions, or congenital deformity [1-6]. Diagnosis of ureterosciatic hernia is difficult by physical examination alone and, therefore, urographic methods (i.e., intravenous urography, retrograde pyelography, and CT) are useful [3-5]. This case was diagnosed by CT and retrograde pyelography. We may decide to follow up our patient with ureterosciatic hernia without treatment because she complains of no symptoms. If she requires surgical management, we will remove the ureter and perform an ureteroureterostomy. Furthermore, reinforcement operations can be performed for treating weak or damaged pelvic fascia. Restoration by ureteroscopy or a ureteral stent, which was used in this case, is a less aggressive treatment for ureterosciatic hernias [1,2]. To the best of our knowledge, there have been no reports regarding the ureteral catheter indwelling period; however, no recurrence of ureterosciatic hernia was observed when the stent had been removed approximately 1 year following stent implantation $[3,4]$. 
Case Reports in

Nephrology

and Dialysis

\begin{tabular}{l|l}
\hline \multicolumn{2}{l|}{ Case Rep Nephrol Dial 2015;5:83-86 } \\
\hline DOI: $10.1159 / 000380944$ & $\begin{array}{l}\text { C } 2015 \text { S. Karger AG, Basel } \\
\text { www.karger.com/cnd }\end{array}$ \\
\hline
\end{tabular}

Yanagi et al.: Treatment of Ureterosciatic Hernia with a Ureteral Stent

\section{References}

1 Weintraub JL, Pappas GM, Romano WJ, et al: Percutaneous reduction of ureterosciatic hernia. AJR Am J Roentgenol 2000;175:181-182.

2 Rommel FM, Boline GB, Huffnagle HW: Ureterosciatic hernia: an anatomical radiographic correlation. J Urol 1993;150:1232-1234.

3 Sugimoto M, Iwai H, Kobayashi T, et al: Ureterosciatic hernia successfully treated by ureteral stent placement. Int J Urol I 2011;18:716-717.

-4 Clemens AJ, Thiel DD, Broderick GA: Ureterosciatic hernia. J Urol 2010;184:1494-1495.

-5 Loffroy R, Bry J, Guiu B, et al: Ureterosciatic hernia: a rare cause of ureteral obstruction visualized by multislice helical computed tomography. Urology 2007;69:385.e1-3.

6 Hsu HL, Huang KH, Chang CC, et al: Hydronephrosis caused by ureterosciatic herniation. Urology 2010;76:1375-1376.
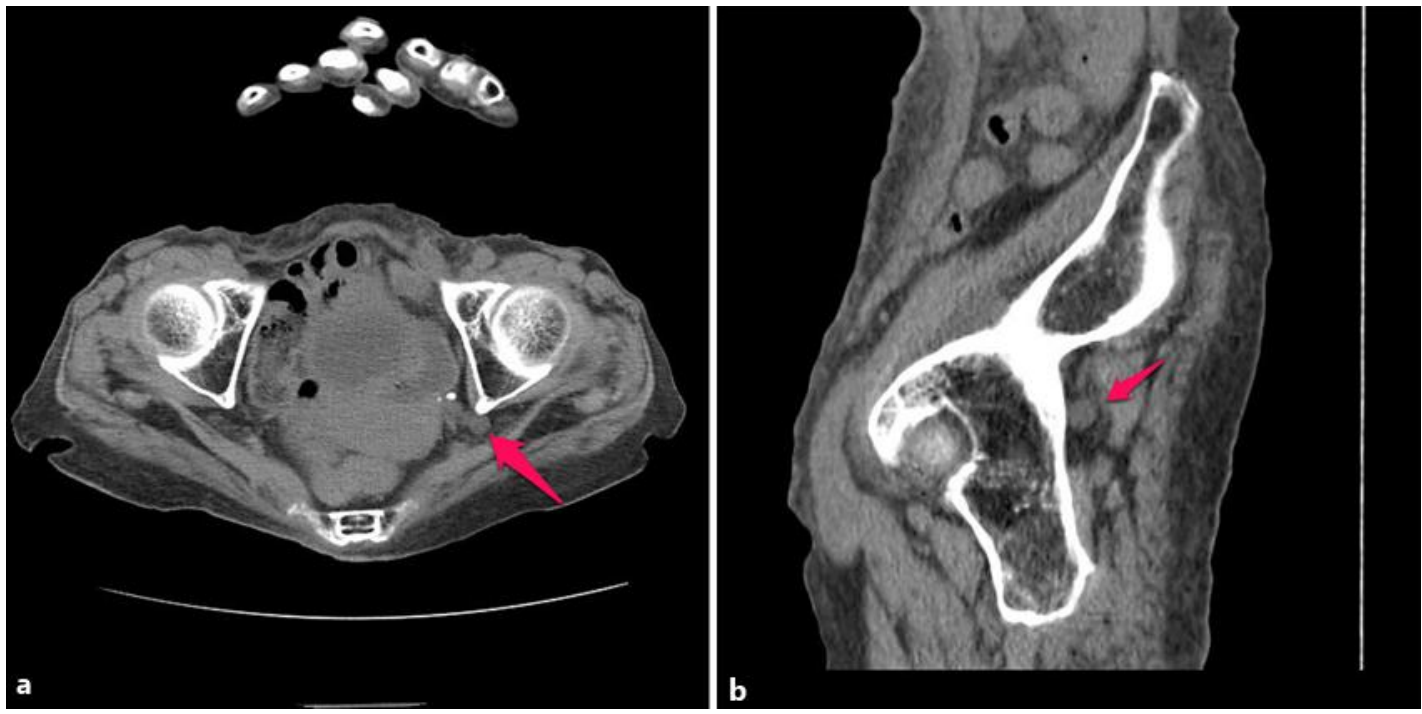

Fig. 1. Plane horizontal (a) and sagittal (b) CT shows that the lower part of the ureter was shifted to the outside of the cavum pelvis minor from the greater sciatic foramen. 
Case Reports in

Nephrology

and Dialysis

\begin{tabular}{l|l}
\hline Case Rep Nephrol Dial 2015;5:83-86 \\
\hline DOI: $10.1159 / 000380944$ & $\begin{array}{l}\text { C 2015 S. Karger AG, Basel } \\
\text { www.karger.com/cnd }\end{array}$ \\
\hline
\end{tabular}

Yanagi et al.: Treatment of Ureterosciatic Hernia with a Ureteral Stent

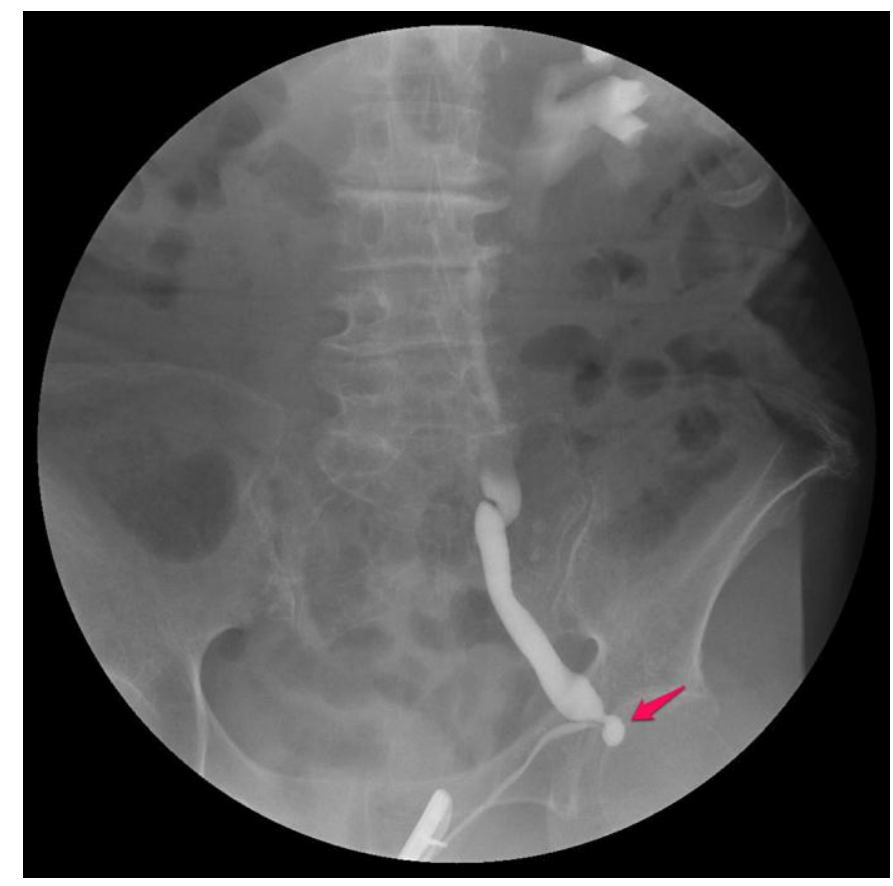

Fig. 2. Retrograde ureterography reveals a tortuous left ureter and the shadow of a constricted mass.
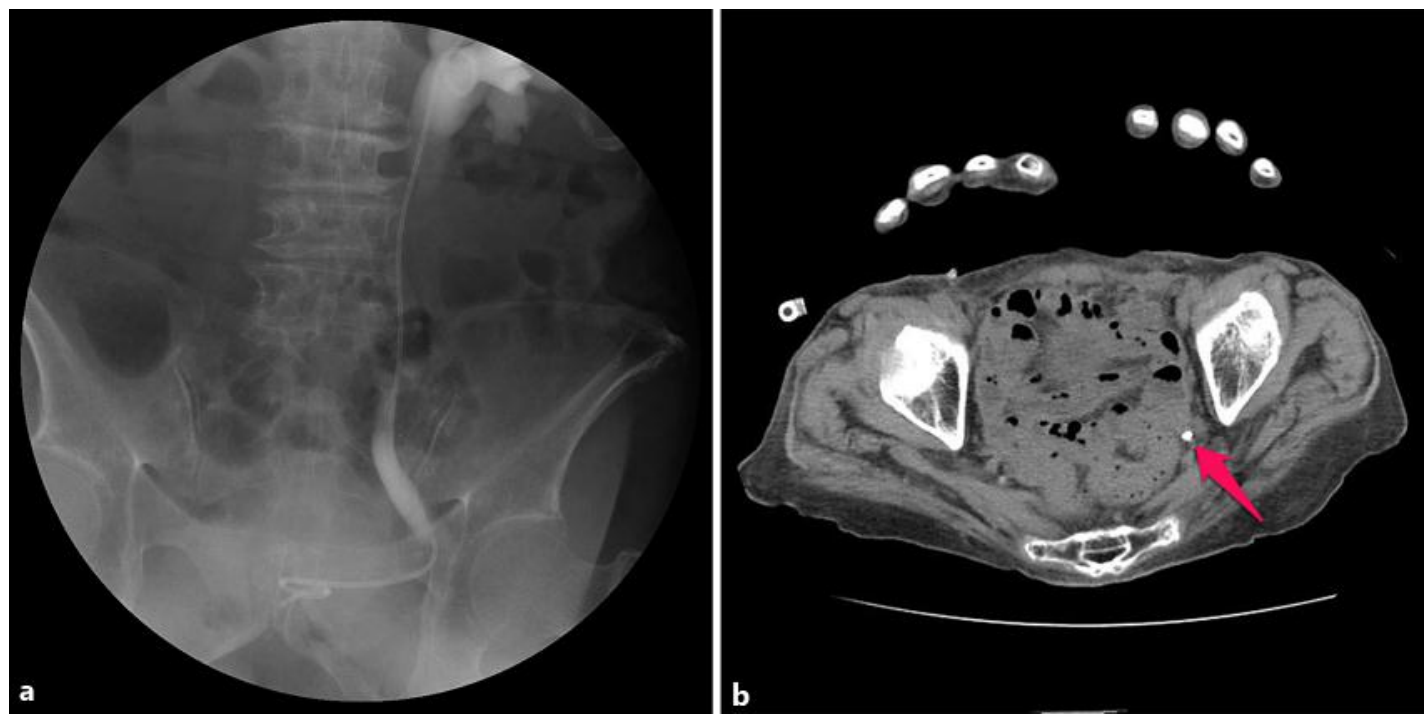

Fig. 3. a, b The double-J stent has returned to the normal position. 